\title{
Using viral vectors to deliver local immunotherapy to glioblastoma
}

\author{
Alexander F. Haddad, BS, Jacob S. Young, MD, and Manish K. Aghi, MD, PhD \\ Department of Neurological Surgery, University of California, San Francisco, California
}

The treatment for glioblastoma (GBM) has not seen significant improvement in over a decade. Immunotherapies target the immune system against tumor cells and have seen success in various cancer types. However, the efficacy of immunotherapies in GBM thus far has been limited. Systemic immunotherapies also carry with them concerns surrounding systemic toxicities as well as penetration of the blood-brain barrier. These concerns may potentially limit their efficacy in GBM and preclude the use of combinatorial immunotherapy, which may be needed to overcome the severe multidimensional immune suppression seen in GBM patients. The use of viral vectors to deliver immunotherapies directly to tumor cells has the potential to improve immunotherapy delivery to the CNS, reduce systemic toxicities, and increase treatment efficacy. Indeed, preclinical studies investigating the delivery of immunomodulators to GBM using viral vectors have demonstrated significant promise. In this review, the authors discuss previous studies investigating the delivery of local immunotherapy using viral vectors. They also discuss the future of these treatments, including the reasoning behind immunomodulator and vector selection, patient safety, personalized therapies, and the need for combinatorial treatment.

https://thejns.org/doi/abs/10.3171/2020.11.FOCUS20859

KEYWORDS oncolytic viruses; glioblastoma; cytokines; treatment; immunotherapy

$\mathrm{T}$ HE treatment of glioblastoma (GBM) includes resection, radiation, and chemotherapy, with only modest changes and improvements over the past decade. ${ }^{1}$ The need for novel treatments is highlighted by the current survival prognosis of 15 months for patients newly diagnosed with GBM. ${ }^{2}$ Immunotherapies, a growing area of cancer research, target the immune system against cancer cells and have had success against other cancer types..$^{3-5}$ Recent studies have refuted the previous canon of the brain's immune-privileged state, indicating that the immune system can access the CNS and may play a role in tumors afflicting it. ${ }^{6}$

These insights have suggested that GBM might be treatable with therapies that stimulate the immune system. As a result, a plethora of novel immunotherapies, from checkpoint inhibitors to immunostimulatory cytokines, are currently in development for the treatment of GBM. ${ }^{3,7}$ However, systemically delivered single-agent immunotherapies have thus far seen limited success in treating GBM, ${ }^{4}$ likely due to the uniquely immunosuppressive GBM tumor microenvironment..$^{3,4,8-11}$ A number of characteristics are thought to contribute to the lack of response to immunotherapies seen in GBM; these include the downregulation of major histocompatibility complex
(MHC) class $\mathrm{I}^{9-11}$ and low GBM tumor mutational burden, which can reduce the number of tumor-associated antigens for the immune system to target. ${ }^{12}$ Indeed, a positive relationship exists between tumor mutational burden and response to immunotherapies across most cancer types; however, this is not observed in GBM, highlighting the severe immunosuppression seen in afflicted patients..$^{13}$ In fact, GBM can lead to both local and systemic immunosuppression. ${ }^{14,15}$ Signaling pathways implicated in GBM immunosuppression include expression of immune checkpoint molecules, transforming growth factor $-\beta$ signaling, STAT3, and expression of other immunosuppressive cytokines by the tumor. In addition, GBM tumors have a low number of tumor-infiltrating $\mathrm{T}$ cells, which can mediate tumor cell death; the $\mathrm{T}$ cells that do infiltrate into the tumors are exhausted and dysfunctional. ${ }^{8,16} \mathrm{GBM}$ patients also have low systemic $\mathrm{T}$ cells due to their sequestration in the bone marrow, contributing to the low antitumor T-cell activity seen..${ }^{15}$ Myeloid cells, including tumor-associated macrophages and myeloid-derived suppressor cells, are additional contributors to the immunosuppression seen in GBM. Increased infiltration of these cells has been associated with reduced survival in GBM. ${ }^{17}$ Myeloid cells and the aforementioned pathways combine to lead to the mul-

ABBREVIATIONS GBM = glioblastoma; HSV = herpes simplex virus; IL = interleukin; MHC = major histocompatibility complex; NK = natural killer; PD-L1 = programmed death ligand $1 ;$ TAA = tumor-associated antigen. 
tidimensional immune suppression seen in $\mathrm{GBM}^{18}$ and its designation as an immunogenically "cold" tumor.

A crucial issue with systemic immunotherapy for GBM is that the doses, or combinations, needed to overcome the severe immunosuppression of GBM $^{15}$ and cross the bloodbrain barrier may be high enough to cause systemic toxicities such as autoimmune side effects or cytokine storm. ${ }^{19,20}$ As a result, there has been increasing interest in local immunotherapies, in which immunostimulatory proteins, such as cytokines, are delivered directly to tumor cells. While many routes of delivery have been explored, such as nanoparticles, scaffolds, and hydrogels, here, we will focus on the use of viral vectors to carry the genetic information for immunostimulatory molecules into tumors. This approach has the unique benefit that the viral vector itself will often stimulate an immune response that the immunostimulatory transgene within the virus can further potentiate. In this review, we discuss relevant preclinical and clinical studies involving this important therapeutic approach for GBM.

\section{Overview of Viral Vectors Used for GBM}

In general, viruses used to treat tumors can be divided into three categories: 1) replication-deficient viruses such as retrovirus or adenovirus, whose therapeutic potential is derived from the gene(s) they deliver; 2) oncolytic viruses such as herpes simplex virus (HSV) or adenovirus, which selectively divide in tumor cells and then lyse and kill the infected cell before releasing progeny viruses; and 3 ) replicating nonlytic viruses such as retrovirus, which selectively divide in tumor cells while releasing progeny viruses in a nonlytic fashion, with the primary therapeutic effect occurring from the gene(s) they deliver. The latter two categories derive their replication selectively for tumor cells in a number of mechanisms, including selectivity for replicating cells and molecular machinery that only activates viral replication in the presence of certain oncogene-associated intracellular gene expression changes.

Any of the three viral categories previously mentioned can stimulate an immune response without the expression of an immunomodulatory transgene. This is most notable for replication-competent oncolytic viruses, which cause lytic tumor cell death, leading to the release of tumorassociated antigens (TAAs), damage-associated molecular patterns, and pathogen-associated molecular patterns. Viral infection can lead to immune stimulation through a variety of pathways, including immunogenic cell death, rather than the more immunogenically silent apoptosis, promoting dendritic cell recruitment, and increasing antigen uptake and presentation, subsequently generating a robust antitumor immune response. ${ }^{21,22}$ However, even replication-deficient or replicating nonlytic viruses can stimulate an immune response to viral envelope proteins, for example, at the time of inoculation for replicationdeficient viruses and throughout the viral life cycle for replicating nonlytic viruses. This immune response can, at times, precipitate a localized inflammatory milieu that can ultimately become antitumoral in nature even if it was not originally targeted against tumor proteins. Indeed, oncolytic viral therapy has been shown to boost the treat- ment efficacy of simultaneously given immunotherapy, leading to the perception of oncolytic viruses as a form of "tumor vaccine." 11,23 Of course, different oncolytic viruses can lead to a spectrum of immune activation phenotypes, which bears careful consideration when deciding on a vector to deliver a therapeutic payload, as discussed in subsequent sections.

\section{Delivering Immunomodulators to GBM Using Viral Vectors}

Immunomodulators have been successfully delivered to tumors to generate an antitumor immune response in multiple cancer types. ${ }^{24,25}$ For example, interleukin (IL)-12, a cytokine with the ability to stimulate a potent antitumor response through natural killer (NK)-cell and T-cell activation, ${ }^{26}$ but with high systemic toxicity, ${ }^{27}$ has been delivered using adenoviruses to a variety of cancers, including hepatocellular carcinoma, medullary thyroid carcinoma, and prostate carcinoma. ${ }^{24}$ IL-12 has also been delivered to GBM in a similar manner. An early paper by Liu et al. described the use of a replication-deficient adenovirus to deliver IL-12 to mice with GL-26 tumors, resulting in a significant survival benefit, with increased intratumoral CD4+ and CD8+ T-cell infiltration. ${ }^{28}$ Hellums et al. reproduced these findings when treating mice implanted with 4C8 tumors with a replication-competent HSV expressing IL-12, showing improved survival and increased CD4+, CD8+, and NK cells at day 7 posttreatment. ${ }^{54}$ As a result, a replication-competent HSV expressing IL-12 (MO32) is now being investigated further in clinical trials. ${ }^{29}$

Subsequent studies have further refined the delivery of IL-12 to the GBM tumor microenvironment using adenoviruses. Barrett et al. designed and delivered an adenovirus carrying the genetic information for IL-12 with a regulatable promoter system that could be turned on using an exogenously administered activator (veledimex). ${ }^{30}$ This resulted in a long-term survival benefit in $65 \%$ of treated mice, although the experiments were performed in the GL261 model, which is thought to be significantly more immunogenic than human GBM. ${ }^{31}$ In addition, the regulatable nature of the system allows for titration of IL-12 levels and increased safety relative to a constitutively expressed construct. In a subsequent phase I clinical trial, 31 patients were administered the IL-12-containing adenovirus, then given veledimex at varying doses and as tolerated. Data from one patient requiring additional resections of their GBM highlighted significant increases in tumor-infiltrating T cells, including both CD3+ and CD3+/CD8+ T cells. In addition, a trend toward increased survival was seen in patients treated with $20 \mathrm{mg}$ of the orally administered activator and less than $20 \mathrm{mg}$ of cumulative dexamethasone dose. As a result of these promising findings, this vector is currently being evaluated in a phase II clinical trial.

Additional cytokines have also been delivered to the GBM tumor microenvironment using viral vectors. Also targeting the T-cell compartment, Jiang et al. used a replication-competent adenovirus (Delta-24-RGD) to deliver OX40L, a costimulatory molecule that can activate prosurvival signaling pathways, support memory T-cell formation, reduce immunosuppressive $\mathrm{T}$ regulatory cells, 
and promote activation of CD8+ and CD4+ T cells and NK cells. ${ }^{32,33}$ When compared with the unmodified Delta-24-RGD, mice treated with Delta-24-RGD-OX40L demonstrated significantly improved survival, highlighting the potential for local immunostimulatory molecule expression to improve treatment efficacy when combined with an oncolytic virus. Intratumoral injection of antiprogrammed death ligand 1 (PD-L1) antibody in combination with Delta-24-RGD-OX40L further improved survival, showing the value of targeting multiple aspects of T-cell dysfunction/suppression seen in GBM by enhancing T-cell activation as well as blocking the action of checkpoint molecules. ${ }^{8,32}$ The same group also generated a Delta-24-RGD carrying the costimulatory ligand GITRL (glucocorticoid-induced TNFR family-related gene ligand, Delta-24-GREAT), which is usually expressed on antigenpresenting cells and similarly supports CD4+ and CD8+ Tcell proliferation and activation through binding to GITR. Also using the GL261 cell line, they demonstrated that administration of Delta-24-GREAT increased infiltrating CD8+ T cells 15 days after initial tumor implantation, with improved survival in treated mice. Interestingly, long-term survivors also demonstrated resistance to rechallenge with GL-261, but not a melanoma cell line, indicating a tumorspecific immune memory response. ${ }^{34}$

Passaro et al. utilized a different approach to locally deliver a checkpoint inhibitor to GBM. ${ }^{35}$ They targeted the PD1/PD-L1 axis, which can lead to suppression of antitumoral T-cell activity. Instead of intratumoral injections of anti-PD-L1, like Jiang et al., ${ }^{32}$ they utilized an oncolytic HSV expressing a single-chain fragment variable antibody against PD-1; this allowed for checkpoint inhibition in combination with tumor cell death caused by the virus. Using both the CT-2A and GL261 models, they showed that mice treated with the HSV expressing PD-1 had a significant survival benefit relative to control mice, with some exhibiting long-term responses and resistance to challenge. Interestingly, however, there was reduced therapeutic response in the CT-2A model, highlighting the relatively low immunogenicity of the model relative to GL261 and the importance of considering model selection when interpreting preclinical findings.

While the previously discussed OX40L, GITRL, IL-12, and PD-1 focus primarily on supporting the T-cell compartment of the immune system against GBM, it is also critical to consider other immune cells in the GBM microenvironment, especially myeloid cells. In fact, the low number of dendritic cells in the GBM microenvironment is thought to contribute to reduced TAA presentation and hinder the development of a sustained immune response against tumor cells. King et al. sought to increase the number and activity of dendritic cells through the delivery of human-soluble FMS-like tyrosine kinase 3 ligand (FLT3L), which supports the development and recruitment of dendritic cells, to the tumor microenvironment. ${ }^{36}$ To accomplish this, they used a defective adenovirus carrying the FLT3L gene in combination with another adenovirus carrying thymidine kinase (a suicide gene), with the thought that ample TAAs would be released following prodrug administration, allowing for subsequent dendritic cell uptake and presentation. Administration of the two viruses to a rat model of multifocal GBM resulted in long-term survival in approximately $70 \%$ of treated animals, highlighting the potential promise of this treatment. Given the promising preclinical findings, this system is now being evaluated in a phase I clinical trial. A complete list of preclinical studies and clinical trials involving viral delivery of immunomodulators can be found in Tables 1 and 2, respectively.

\section{Limitations of Preclinical Studies}

Despite exciting preclinical studies, results should be interpreted while also considering the specific GBM model utilized. Accurate modeling is critical in identifying possible side effects as well as determining the potential efficacy of a viral treatment. A number of promising preclinical immunotherapies for GBM have seen limited success on application in the clinical setting, highlighting a disconnect between murine models commonly utilized to test novel treatments and human GBM. ${ }^{37}$ Of the preclinical studies discussed in this review, many utilized the GL261 model which differs from human GBM in a variety of ways, including in its response to immunotherapies. In fact, GL261 has a significantly higher tumor mutational burden, MHC class I expression, and T-cell infiltration relative to what is seen in most human GBM tumors. ${ }^{38}$ As a result, studies utilizing the GL261 model, as well as other models induced through the use of carcinogens (which frequently have higher tumor mutational burdens), should be interpreted with some caution. Murine models induced through other mechanisms, including the manipulation of oncogene expression, may more accurately represent the GBM immune tumor microenvironment and response to immunotherapies. ${ }^{31}$ Additionally, murine models frequently fail to recapitulate the genetics or intratumoral heterogeneity of human GBM, both of which can affect viral replication, viral spread through a tumor, and transgene expression. Thus, patient-derived xenograft (PDX) models, which can more accurately replicate these characteristics, should be used to evaluate viral vectors. Although "humanized" PDX models can be made using peripheral blood mononuclear cells from the same patient as the GBM tumor cells, recapitulating the immune-GBM interface, this technology is associated with high costs and is still under development in GBM. ${ }^{39}$ As a result, consideration should be given to using PDX models to evaluate viral kinetics and transgene expression, in conjunction with a syngeneic model, such as the poorly immunogenic SB28 model, ${ }^{31}$ to evaluate the effect of transgene expression on the immune system and immune-mediated tumor cell killing. The combination of these two model types allows for a more holistic view of novel viral immunotherapies and preclinical results that might better predict clinical efficacy.

\section{The Viral Vector Itself-Should It Be Immunogenic or Immunologically Silent?}

While initial proponents of immunomodulatory gene therapy argued that the immunogenicity of the virus would synergize with the immunostimulatory gene, the potential for immunotherapies to have a negative impact on viral delivery should also be considered. ${ }^{40}$ Type I in- 
TABLE 1. Preclinical studies investigating the delivery of immunomodulators using viral vectors

\begin{tabular}{|c|c|c|c|c|c|c|}
\hline $\begin{array}{l}\text { Authors } \\
\& \text { Year }\end{array}$ & Immunomodulator & Immune Target & Virus & Model & $\begin{array}{l}\text { Replication } \\
\text { Competent or } \\
\text { Defective }\end{array}$ & Outcome \\
\hline $\begin{array}{l}\text { Liu et al., } \\
2002^{28}\end{array}$ & IL-12 & $\begin{array}{l}\text { T-cell proliferation \& } \\
\text { activation }\end{array}$ & Adenovirus & GL-26 & Defective & $\begin{array}{l}\text { Improved survival in treated mice. } \\
\text { Increased intratumoral CD4+ \& CD8+ T cells. }\end{array}$ \\
\hline $\begin{array}{l}\text { Barrett et al., } \\
2018^{30}\end{array}$ & $\begin{array}{l}\text { IL-12 controlled by regu- } \\
\text { latable RheoSwitch } \\
\text { Therapeutic System }\end{array}$ & $\begin{array}{l}\text { T-cell proliferation \& } \\
\text { activation }\end{array}$ & Adenovirus & GL-261 & Defective & $\begin{array}{l}\text { Improved survival in treated mice. } \\
\text { Increased tumor infiltrating CD8+ T cells. }\end{array}$ \\
\hline $\begin{array}{l}\text { Hellums et } \\
\text { al., } 2005^{54}\end{array}$ & IL-12 & $\begin{array}{l}\text { T-cell proliferation \& } \\
\text { activation }\end{array}$ & HSV & $4 \mathrm{C} 8$ & Competent & $\begin{array}{l}\text { Improved survival in treated mice. } \\
\text { Increased intratumoral CD4+ \& CD8+ T cells } \\
\quad \text { \& NK cells at day } 7 \text { posttreatment. }\end{array}$ \\
\hline $\begin{array}{l}\text { Jiang et al., } \\
2017^{32}\end{array}$ & OX40L & $\begin{array}{l}\text { Costimulatory mole- } \\
\text { cule T-cell survival } \\
\text { \& activation }\end{array}$ & Adenovirus & GL-261 & Competent & $\begin{array}{l}\text { Improved survival in treated mice. } \\
\text { Increased intratumoral CD4+ \& CD8+ T cells. }\end{array}$ \\
\hline $\begin{array}{l}\text { Rivera- } \\
\text { Molina et al., } \\
2019^{34}\end{array}$ & GITRL & $\begin{array}{l}\text { Costimulatory mol- } \\
\text { ecule promoting } \\
\text { T-cell proliferation } \\
\text { \& activation }\end{array}$ & Adenovirus & GL-261 & Competent & $\begin{array}{l}\text { Improved survival in treated mice w/ } \\
\text { resistance to rechallenge in long-term } \\
\text { survivors. } \\
\text { Increased central memory CD8+ T cells. }\end{array}$ \\
\hline $\begin{array}{l}\text { Passaro et } \\
\text { al., } 2019^{35}\end{array}$ & $\begin{array}{l}\text { Anti-PD-1 single-chain } \\
\text { fragment variable } \\
\text { antibody }\end{array}$ & $\begin{array}{l}\text { Immune checkpoint } \\
\text { blockade }\end{array}$ & HSV & $\begin{array}{l}\text { GL-261 } \\
\& \text { CT-2A }\end{array}$ & Competent & Improved survival in treated mice. \\
\hline $\begin{array}{l}\text { King et al., } \\
2008^{36}\end{array}$ & FLT3L & $\begin{array}{l}\text { Dendritic cell matura- } \\
\text { tion \& proliferation }\end{array}$ & Adenovirus & CNS-1 & Defective & $\begin{array}{l}\text { Improved survival in rats treated w/ combina- } \\
\text { tion of AdFLT3L \& AdTk. }\end{array}$ \\
\hline
\end{tabular}

terferons, and additional facets of the host innate immune response, play a significant role in local antiviral immune responses, ${ }^{21,41}$ and, while traditionally thought to be downregulated in $\mathrm{GBM},{ }^{42,43}$ they have the potential to be increased by immunotherapies. In addition, the targeting of viral antigens and killing of infected tumor cells by the immune system can lead to a reduction in viral spread through the tumor. While control of virus spread and the reduced presence of viral antigens may be useful in the setting of epitope focusing by the immune system on tumor antigens, ${ }^{21}$ viral clearance may be counterproductive when using a viral vector to deliver a therapeutic agent to the local tumor microenvironment. Instead, vectors that can better avoid clearance by the immune system may be preferred. Specific viruses, such as replicating retroviruses, may be more adept than other viruses at evading antiviral immune responses, further emphasizing the importance of considering the type of viral vector used to deliver an immunotherapy. ${ }^{44}$ Replication-incompetent viruses may also lead to decreased stimulation of the immune system and viral clearance, though at the cost of potentially reduced payload delivery to tumor cells. ${ }^{45}$ Future studies should consider the balance between treatment efficacy and viral clearance, especially in the setting of combination immunotherapy. The development of more immunologically "silent" vectors to promote widespread delivery of therapeutic genes may also be considered.

\section{Safety Considerations for Patients}

Despite the promise of preclinical studies, concerns surrounding the safety of viral immunotherapies have also been raised. During a phase I clinical trial investigating the use of the aforementioned replication-deficient adenovirus carrying IL-12, higher doses of the oral activator were associated with increased adverse events, including cytokine release syndrome, highlighting the potential risks of these treatments. ${ }^{46}$ However, all adverse events were reversible on discontinuation of the oral activator. As a result of the closed intracranial space, and Monro-Kellie hypothesis, any treatments with the potential to cause significant immune cell infiltration and associated brain edema should be considered with caution. The use of regulatable systems (such as in Chiocca et al. ${ }^{46}$ ) or tumor-specific promoters increases vector safety and should be considered in future investigations. In addition, the utilization of supportive medication, such as dexamethasone, to reduce patient symptoms during viral immunotherapy should be considered with caution, given the ability of dexamethasone to suppress the immune system and potentially reduce associated treatment benefits. This is highlighted again by Chiocca et al., where patients with $>20 \mathrm{mg}$ of cumulative dexamethasone dosing trended toward reduced survival when compared with patients who received $<20 \mathrm{mg}$. As viral immunotherapies move toward combinatorial treatments with multiple immunomodulators being used in the same system, the risk of adverse events may also increase. As a result, additional investigation into safer delivery systems or temporizing treatments should be performed, considering the balance between treatment efficacy and patient safety.

\section{Future Directions of GBM Local Viral Immunotherapy}

Using viral vectors to deliver local immunotherapies to 
TABLE 2. Clinical trials investigating the delivery of immunomodulators using viral vectors

\begin{tabular}{|c|c|c|c|c|c|c|}
\hline Treatment & $\begin{array}{l}\text { No. of } \\
\text { Patients }\end{array}$ & $\begin{array}{l}\text { Replication Competent } \\
\text { or Defective }\end{array}$ & $\begin{array}{l}\text { Primary Endpoint } \\
\text { or Outcome }\end{array}$ & Result of Primary Outcome & $\begin{array}{l}\text { ClinicalTrials.gov } \\
\text { Identifier }\end{array}$ & $\begin{array}{l}\text { Current } \\
\text { Status }\end{array}$ \\
\hline \multicolumn{7}{|l|}{ Phase I trials } \\
\hline $\begin{array}{l}\text { Ad-RTS-hIL-12 plus } \\
\text { veledimex }\end{array}$ & 36 & Defective & $\begin{array}{l}\text { Safety \& } \\
\text { tolerability }\end{array}$ & Not posted & NCT03679754 & $\begin{array}{l}\text { Active, not } \\
\text { recruiting }\end{array}$ \\
\hline $\begin{array}{l}\text { Ad-RTS-hlL-12 plus } \\
\text { veledimex in } \\
\text { combination w/ } \\
\text { nivolumab }\end{array}$ & 21 & Defective & $\begin{array}{l}\text { Safety \& } \\
\text { tolerability }\end{array}$ & $\begin{array}{l}\text { Similar safety profile to Ad-RTS-hIL-12 } \\
\text { plus veledimex alone }{ }^{46,55}\end{array}$ & NCT03636477 & $\begin{array}{l}\text { Active, not } \\
\text { recruiting }\end{array}$ \\
\hline $\begin{array}{l}\text { Ad-RTS-hIL-12 plus } \\
\text { veledimex }\end{array}$ & $\sim 24$ & Defective & $\begin{array}{l}\text { Safety \& } \\
\text { tolerability }\end{array}$ & Not posted & NCT03330197 & $\begin{array}{l}\text { Active, not } \\
\text { recruiting }\end{array}$ \\
\hline $\begin{array}{l}\text { Ad-RTS-hIL-12 plus } \\
\text { veledimex }\end{array}$ & $\sim 48$ & Defective & $\begin{array}{l}\text { Safety \& } \\
\text { tolerability }\end{array}$ & $\begin{array}{l}\text { Frequency of AEs correlated w/ veledi- } \\
\text { mex dosing, reversed when veledimex } \\
\text { was stopped; median overall survival } \\
16.7 \text { mos in patients receiving } \leq 20 \mathrm{mg} \\
\text { dexamethasone }{ }^{46}\end{array}$ & NCT02026271 & $\begin{array}{l}\text { Active, not } \\
\text { recruiting }\end{array}$ \\
\hline $\begin{array}{l}\text { Dose escalation of } \\
\text { Ad-hCMV-TK \& } \\
\text { Ad-hCMV-Flt3L }\end{array}$ & 19 & Defective & $\begin{array}{l}\text { Tolerability \& } \\
\text { survival duration }\end{array}$ & Minimal tolerated dose not reached ${ }^{56}$ & NCT01811992 & $\begin{array}{l}\text { Active, not } \\
\text { recruiting }\end{array}$ \\
\hline $\begin{array}{l}\text { HSV M032 } \\
\text { producing IL-12 }\end{array}$ & 36 & Competent & $\begin{array}{c}\text { Minimal tolerated } \\
\text { dose }\end{array}$ & Not posted & NCT02062827 & Recruiting \\
\hline \multicolumn{7}{|l|}{ Phase II trial } \\
\hline $\begin{array}{l}\text { Ad-RTS-hIL-12 plus } \\
\text { veledimex \& } \\
\text { cemiplimab-rwlc }\end{array}$ & 30 & Defective & $\begin{array}{l}\text { Overall survival } \\
\quad \& \text { safety }\end{array}$ & Not posted & NCT04006119 & Recruiting \\
\hline
\end{tabular}

$\mathrm{AE}=$ adverse event.

the GBM tumor microenvironment carries a number of advantages relative to systemically administered immunotherapies, including reducing the risk of systemic side effects and potentially leading to a higher intratumoral concentration of the therapeutic molecule. These approaches are still in their relative infancy, and there are a number of future directions that should be considered.

First, immunomodulatory gene therapy approaches for GBM should consider the entire immune profile of GBM and not just its dysfunction in a single immunological compartment such as $\mathrm{T}$ cells. As previously discussed, the GBM tumor microenvironment is one with multidimensional immune suppression, from T-cell exhaustion and dysfunction to the presence of immunosuppressive myeloid cells. These characteristics should be considered when evaluating which immunomodulators to deliver to the microenvironment. Ideally, viral immunotherapy would result in the release of TAAs, support of T-cellmediated tumor cell death, and reductions in immunosuppressive cell types and signaling pathways. As previously mentioned, many of the preclinical studies investigating local delivery of immunomodulators in GBM thus far have focused primarily on T-cell activation and proliferation, with only FLT3L as of yet targeting dendritic cells. As a result, future investigations should also work to stimulate anti-tumoral myeloid cells (such as antigenpresenting cells) through the delivery of cytokines, such as FLT3L, GMCSF, toll-like receptor stimulators, or others. In addition, immunomodulators that reduce the number or phenotype of immunosuppressive myeloid cells in the tumor microenvironment may also be beneficial.

Combining multiple immunomodulatory genes should also be considered. Single-agent immunotherapies, including systemic anti-PD-1 treatment ${ }^{4}$ and local delivery of IL12 in an adenovirus ${ }^{46}$ have had limited success in clinical trials, likely due to the multifaceted immunosuppression in GBM. Thus, future viral therapies should work to deliver multiple immunomodulators to tumor cells, each targeting a different aspect of the immune system. Porter et al. provided a potential example of what such a system might look like in treating various cancer types, albeit not GBM, when they delivered a tumor-targeting bispecific T-cell engager (BiTE), IL-12, and PD-L1 antibody in a single adenovirus vector. ${ }^{47}$ Their vector demonstrated significantly improved survival when combined with an HER2 CAR T cell as it provided cytokine support and an immune checkpoint blockade, with the BiTE also providing an additional modality of T-cell targeting to tumor cells. A similar system could be used in GBM, ideally targeting multiple compartments of the immune microenvironment. Stimulating specific immune compartments, such as the T-cell compartment, through multiple signaling modalities that might be additive, as has been seen with virotherapy combining OX40L and 4-1BBL in multiple myeloma ${ }^{48}$ also deserves additional investigation in GBM. In addition, using oncolytic viruses to deliver epitopes for CAR T cells ${ }^{49}$ is an interesting possibility for future investigation in GBM. Immunomodulatory gene therapy could also be combined 
with nonimmunological gene therapy. For example, viral treatments delivering suicide genes, such as Toca 511, have been shown to reduce levels of immunosuppressive myeloid cells as well as lead to the release of TAAs into the tumor microenvironment, making them interesting candidates for combination with locally delivered immunotherapies. ${ }^{50}$ Combinatorial oncolytic virus immunotherapy will undoubtedly continue to see use throughout various cancer types, including to treat GBM.

The combination of viral vectors carrying an immunomodulatory gene(s) with systemic immunotherapies may also hold promise. While systemic immunotherapies, such as checkpoint inhibitors, have had limited success in GBM, there is likely a benefit of combining them with localized viral delivery of an immunomodulatory gene, thereby turning a cold tumor like GBM into a hot tumor responsive to checkpoint blockade. This concept was demonstrated by Nakao et al., who combined an oncolytic vaccinia virus encoding for IL-7 and IL-12 with systemic checkpoint inhibitor treatment. ${ }^{51}$ They showed that administration of the viral treatment sensitized previously checkpoint inhibitor-resistant colon cancer tumors, allowing for complete regression in the majority of tumors that received combinatorial treatment with an anti-PD-1 antibody. Similar results may be seen in GBM when combining viral immunotherapy supporting T-cell proliferation, activation, and/or tumor infiltration with a systemically administered checkpoint inhibitor.

Finally, future studies should also investigate whether these approaches can be applied and modified based on specific tumor gene mutations or microenvironment profiles in a precision medicine manner. A long-standing debate in tumor immunology has to do with the concept of personalized immunotherapy. ${ }^{52}$ This began as a debate over whether tumor vaccines should target shared versus unique antigens in cancer. However, in light of studies showing how tumor mutations affect the immune microenvironment, ${ }^{53}$ the application of nonvaccine immunotherapies such as immunomodulatory gene therapy based on an individual patient's tumor molecular or microenvironment profile is worthy of further investigation.

\section{Conclusions}

The use of viral vectors to deliver immunotherapies is a growing area of research within neurooncology. Most current investigations focus on delivery of a single immunomodulator and on the T-cell compartment of the immune system. However, future studies will likely involve the use of combinatorial immunotherapy, targeting multiple aspects of the severe immunosuppression seen in GBM, as well as personalized treatments. In addition, the relationship between mechanisms to improve patient safety, including regulatable systems for transgene expression as well as tumor-specific promoters, and treatment efficacy should also continue to be explored.

\section{References}

1. Stupp R, Mason WP, van den Bent MJ, et al. Radiotherapy plus concomitant and adjuvant temozolomide for glioblastoma. N Engl J Med. 2005;352(10):987-996.
2. Ostrom QT, Cioffi G, Gittleman H, et al. CBTRUS statistical report: primary brain and other central nervous system tumors diagnosed in the United States in 2012-2016. Neuro Oncol. 2019;21(5)(suppl 5):v1-v100.

3. Young JS, Dayani F, Morshed RA, et al. Immunotherapy for high grade gliomas: a clinical update and practical considerations for neurosurgeons. World Neurosurg. 2019;124:397-409.

4. Reardon DA, Brandes AA, Omuro A, et al. Effect of nivolumab vs bevacizumab in patients with recurrent glioblastoma: the CheckMate 143 Phase 3 randomized clinical trial. JAMA Oncol. 2020;6(7):1003-1010.

5. Montoya ML, Kasahara N, Okada H. Introduction to immunotherapy for brain tumor patients: challenges and future perspectives. Neurooncol Pract. 2020;7(5):465-476.

6. Louveau A, Smirnov I, Keyes TJ, et al. Structural and functional features of central nervous system lymphatic vessels. Nature. 2015;523(7560):337-341.

7. Lim M, Xia Y, Bettegowda C, Weller M. Current state of immunotherapy for glioblastoma. Nat Rev Clin Oncol. 2018; 15(7):422-442.

8. Woroniecka KI, Rhodin KE, Chongsathidkiet P, et al. T-cell dysfunction in glioblastoma: applying a new framework. Clin Cancer Res. 2018;24(16):3792-3802.

9. Aldape K, Zadeh G, Mansouri S, et al. Glioblastoma: pathology, molecular mechanisms and markers. Acta Neuropathol. 2015;129(6):829-848.

10. D’Alessio A, Proietti G, Sica G, Scicchitano BM. Pathological and molecular features of glioblastoma and its peritumoral tissue. Cancers (Basel). 2019;11(4):E469.

11. Facoetti A, Nano R, Zelini P, et al. Human leukocyte antigen and antigen processing machinery component defects in astrocytic tumors. Clin Cancer Res. 2005;11(23):8304-8311.

12. Cristescu R, Mogg R, Ayers M, et al. Pan-tumor genomic biomarkers for PD-1 checkpoint blockade-based immunotherapy. Science. 2018;362(6411):eaar3593.

13. Samstein RM, Lee C-H, Shoushtari AN, et al. Tumor mutational load predicts survival after immunotherapy across multiple cancer types. Nat Genet. 2019;51(2):202-206.

14. Nduom EK, Weller M, Heimberger AB. Immunosuppressive mechanisms in glioblastoma. Neuro Oncol. 2015;17(7 Suppl): vii9-vii14.

15. Chongsathidkiet $P$, Jackson C, Koyama S, et al. Sequestration of $\mathrm{T}$ cells in bone marrow in the setting of glioblastoma and other intracranial tumors. Nat Med. 2018;24(9):1459-1468.

16. Woroniecka K, Chongsathidkiet P, Rhodin K, et al. T-cell exhaustion signatures vary with tumor type and are severe in glioblastoma. Clin Cancer Res. 2018;24(17):4175-4186.

17. Alban TJ, Alvarado AG, Sorensen MD, et al. Global immune fingerprinting in glioblastoma patient peripheral blood reveals immune-suppression signatures associated with prognosis. JCI Insight. 2018;3(21):122264.

18. Ding AS, Routkevitch D, Jackson C, Lim M. Targeting myeloid cells in combination treatments for glioma and other tumors. Front Immunol. 2019;10:1715.

19. Filley AC, Henriquez M, Dey M. Recurrent glioma clinical trial, CheckMate-143: the game is not over yet. Oncotarget. 2017;8(53):91779-91794.

20. Kennedy LB, Salama AKS. A review of cancer immunotherapy toxicity. CA Cancer J Clin. 2020;70(2):86-104.

21. Russell SJ, Barber GN. Oncolytic viruses as antigen-agnostic cancer vaccines. Cancer Cell. 2018;33(4):599-605.

22. Lichty BD, Breitbach CJ, Stojdl DF, Bell JC. Going viral with cancer immunotherapy. Nat Rev Cancer. 2014;14(8):559-567.

23. Ribas A, Dummer R, Puzanov I, et al. Oncolytic virotherapy promotes intratumoral T cell infiltration and improves antiPD-1 immunotherapy. Cell. 2017;170(6):1109-1119.e10.

24. Qian C, Xin YL, Prieto J. Therapy of cancer by cytokines mediated by gene therapy approach. Cell Research. 2006; 16(2):182-188. 
25. Liu L, Wang S, Shan B, et al. Advances in viral-vector systemic cytokine gene therapy against cancer. Vaccine. 2010; 28(23):3883-3887.

26. Berraondo P, Etxeberria I, Ponz-Sarvise M, Melero I. Revisiting interleukin-12 as a cancer immunotherapy agent. Clin Cancer Res. 2018;24(12):2716-2718.

27. Trinchieri G. Interleukin-12: a cytokine at the interface of inflammation and immunity. Adv Immunol. 1998;70:83-243.

28. Liu Y, Ehtesham M, Samoto K, et al. In situ adenoviral interleukin 12 gene transfer confers potent and long-lasting cytotoxic immunity in glioma. Cancer Gene Ther. 2002;9(1):9-15.

29. Patel DM, Foreman PM, Nabors LB, et al. Design of a phase I clinical trial to evaluate M032, a genetically engineered HSV-1 expressing IL-12, in patients with recurrent/progressive glioblastoma multiforme, anaplastic astrocytoma, or gliosarcoma. Hum Gene Ther Clin Dev. 2016;27(2):69-78.

30. Barrett JA, Cai H, Miao J, et al. Regulated intratumoral expression of IL-12 using a RheoSwitch Therapeutic System ${ }^{\circledR}$ (RTS $\left.{ }^{\circledR}\right)$ gene switch as gene therapy for the treatment of glioma. Cancer Gene Ther. 2018;25(5-6):106-116.

31. Genoud V, Marinari E, Nikolaev SI, et al. Responsiveness to anti-PD-1 and anti-CTLA-4 immune checkpoint blockade in SB28 and GL261 mouse glioma models. OncoImmunology. 2018;7(12):e1501137.

32. Jiang H, Rivera-Molina Y, Gomez-Manzano C, et al. Oncolytic adenovirus and tumor-targeting immune modulatory therapy improve autologous cancer vaccination. Cancer Res. 2017;77(14):3894-3907.

33. Alves Costa Silva C, Facchinetti F, Routy B, Derosa L. New pathways in immune stimulation: targeting OX40. ESMO Open. 2020;5(1):e000573.

34. Rivera-Molina Y, Jiang H, Fueyo J, et al. GITRL-armed Delta-24-RGD oncolytic adenovirus prolongs survival and induces anti-glioma immune memory. Neurooncol Adv. 2019; 1(1):vdz009.

35. Passaro C, Alayo Q, De Laura I, et al. Arming an oncolytic herpes simplex virus type 1 with a single-chain fragment variable antibody against PD-1 for experimental glioblastoma therapy. Clin Cancer Res. 2019;25(1):290-299.

36. King GD, Muhammad AKMG, Curtin JF, et al. Flt3L and TK gene therapy eradicate multifocal glioma in a syngeneic glioblastoma model. Neuro Oncol. 2008;10(1):19-31.

37. Johnson JI, Decker S, Zaharevitz D, et al. Relationships between drug activity in NCI preclinical in vitro and in vivo models and early clinical trials. Br J Cancer. 2001;84(10):1424-1431.

38. Johanns TM, Ward JP, Miller CA, et al. Endogenous neoantigen-specific CD8 T cells identified in two glioblastoma models using a cancer immunogenomics approach. Cancer Immunol Res. 2016;4(12):1007-1015.

39. Buqué A, Galluzzi L. Modeling tumor immunology and immunotherapy in mice. Trends Cancer. 2018;4(9):599-601.

40. Lemos de Matos A, Franco LS, McFadden G. Oncolytic viruses and the immune system: the dynamic duo. Mol Ther Methods Clin Dev. 2020;17:349-358.

41. Han J, Chen X, Chu J, et al. TGF $\beta$ treatment enhances glioblastoma virotherapy by inhibiting the innate immune response. Cancer Res. 2015;75(24):5273-5282.

42. Alain T, Lun X, Martineau Y, et al. Vesicular stomatitis virus oncolysis is potentiated by impairing mTORC1-dependent type I IFN production. Proc Natl Acad Sci U S A. 2010; 107(4):1576-1581.

43. Critchley-Thorne RJ, Simons DL, Yan N, et al. Impaired interferon signaling is a common immune defect in human cancer. Proc Natl Acad Sci U S A. 2009;106(22):9010-9015.
44. Lin AH, Burrascano C, Pettersson PL, et al. Blockade of type I interferon (IFN) production by retroviral replicating vectors and reduced tumor cell responses to IFN likely contribute to tumor selectivity. J Virol. 2014;88(17):10066-10077.

45. Kim JW, Miska J, Young JS, et al. A comparative study of replication-incompetent and-competent adenoviral therapymediated immune response in a murine glioma model. Mol Ther Oncolytics. 2017;5:97-104.

46. Chiocca EA, Yu JS, Lukas RV, et al. Regulatable interleukin-12 gene therapy in patients with recurrent high-grade glioma: results of a phase 1 trial. Sci Transl Med. 2019; 11(505):eaaw5680.

47. Porter CE, Rosewell Shaw A, Jung Y, et al. Oncolytic adenovirus armed with BiTE, cytokine, and checkpoint inhibitor enables CAR T cells to control the growth of heterogeneous tumors. Mol Ther. 2020;28(5):1251-1262.

48. Wenthe J, Naseri S, Hellström AC, et al. Immunostimulatory oncolytic virotherapy for multiple myeloma targeting 4-1BB and/or CD40. Cancer Gene Ther. 2020;27(12):948-959.

49. Park AK, Fong Y, Kim SI, et al. Effective combination immunotherapy using oncolytic viruses to deliver CAR targets to solid tumors. Sci Transl Med. 2020;12(559):eaaz1863.

50. Hiraoka K, Inagaki A, Kato Y, et al. Retroviral replicating vector-mediated gene therapy achieves long-term control of tumor recurrence and leads to durable anticancer immunity. Neuro Oncol. 2017;19(7):918-929.

51. Nakao S, Arai Y, Tasaki M, et al. Intratumoral expression of IL-7 and IL-12 using an oncolytic virus increases systemic sensitivity to immune checkpoint blockade. Sci Transl Med. 2020;12(526):eaax7992.

52. Manjili MH. The premise of personalized immunotherapy for cancer dormancy. Oncogene. 2020;39(22):4323-4330.

53. Parsa AT, Waldron JS, Panner A, et al. Loss of tumor suppressor PTEN function increases B7-H1 expression and immunoresistance in glioma. Nat Med. 2007;13(1):84-88.

54. Hellums EK, Markert JM, Parker JN, et al. Increased efficacy of an interleukin-12-secreting herpes simplex virus in a syngeneic intracranial murine glioma model. Neuro Oncol. 2005;7(3):213-224.

55. Chiocca EA, Lukas RV, Rao G, et al. Evaluation of controlled IL-12 in combination with a PD-1 inhibitor in subjects with recurrent glioblastoma. J Clin Oncol. 2019;37(15)(suppl):2020.

56. Lowenstein PR, Orringer DA, Sagher O, et al. First-in-human phase I trial of the combination of two adenoviral vectors expressing HSV1-TK and FLT3L for the treatment of newly diagnosed resectable malignant glioma: initial results from the therapeutic reprogramming of the brain immune system. J Clin Oncol. 2019;37(15)(suppl):2019.

\section{Disclosures}

The authors report no conflict of interest concerning the materials or methods used in this study or the findings specified in this paper.

\section{Author Contributions}

Conception and design: all authors. Drafting the article: Haddad, Young. Critically revising the article: all authors. Reviewed submitted version of manuscript: all authors. Study supervision: Aghi.

\section{Correspondence}

Manish K. Aghi: University of California, San Francisco, CA. manish.aghi@ucsf.edu. 